Pesq. Vet. Bras. 37(2):183-194, fevereiro 2017 DOI: 10.1590/S0100-736X2017000200014

\title{
Aspectos morfológicos e ultraestruturais de células sanguíneas de Crotalus durissus terrificus ${ }^{1}$
}

\author{
Lívia M. Kindlovits², Farlen J.B. Miranda ${ }^{3}$, João Claudio Damasceno-Sá ${ }^{3}$, \\ Renato A. Da Matta ${ }^{3}$ e Nádia R.P. Almosny ${ }^{2 *}$
}

\begin{abstract}
Kindlovits L.M., Miranda F.J.B., Damasceno-Sá J.C., Da Matta R.A. \& Almosny N.R.P. 2017. [Morphological and ultrastructural aspects of Crotalus durissus terrificus blood cells.] Aspectos morfológicos e ultraestruturais de células sanguíneas de Crotalus durissus terrificus. Pesquisa Veterinária Brasileira 37(2):183-194. Departamento de Patologia Clínica Veterinária, Faculdade de Veterinária, Universidade Federal Fluminense, Rua Vital Brazil Filho 64, Niterói, RJ 24230-360, Brazil. E-mail: almosny@gmail.com

Hematological evaluation, important for the diagnostic by the small domestic animal clinician, has become common in wildlife clinic, and for handling and study of the physiology of various species. Given the increased demand for drug production of pharmaceutical importance, the breeding of venomous snakes has become common and is already recognized as production. Knowledge of the management and clinics of snakes is still insufficient and their mortality is high. Although some hematological studies have already been conducted in the rattlesnake (Crotalus durissus), the analyzed data are still insufficient, especially with respect to the characterization of blood cells, and few electron microscopy studies have been performed on snakes. In order to characterize morphologically blood cells with light and ultrastructural microscopy, blood samples from 52 individuals of subspecies of Crotalus durissus terrificus were collected to perform blood smears and ultrastructural evaluation. It was concluded that hematologic Giemsa staining allows morphological evaluation and differentiation of the blood cells as well as of snake hemoparasites. The ultrastructural evaluation will highlight the cell organelles and differentiation between cells, including leukocyte types; although still further studies are needed to elucidate the hypothesis of eosinophils in the species studied as also is necessary a better characterization of azurophilic beads to confirm a possible difference between the typical monocyte and the azurophilic.
\end{abstract}

INDEX TERMS: Pathology, electronic microscopy, hematology, blood cells, leukocytes, snake.

RESUMO.- A avaliação hematológica, de importância comprovada como um meio auxiliar de diagnóstico ao clínico de pequenos animais domésticos, vem se tornando comum em animais selvagens não apenas para a clínica, mas para a avaliação do manejo e como estudo auxiliar para a fisiologia das várias espécies. Tendo em vista o aumento da demanda para a produção de várias drogas de importância farmacêutica, a criação de serpentes peçonhentas vem se

\footnotetext{
${ }^{1}$ Recebido em 6 de agosto de 2015.

Aceito para publicação em 11 de agosto de 2016.

2 Departamento de Patologia Clínica Veterinária, Faculdade de Veterinária, Universidade Federal Fluminense, Rua Vital Brazil Filho 64, Niterói, RJ 24230-360, Brazil. *Autor para correspondência: almosny@gmail.com

${ }^{3}$ Laboratório de Biologia Celular e Tecidual, Universidade Estadual do Norte Fluminense Darcy Ribeiro, Avenida Alberto Lamego 2000, Parque Califórnia, Campos dos Goytacazes, RJ 28013-602, Brazil.
}

tornando comum a ponto destes animais já serem reconhecidos como sendo de produção. 0 conhecimento do manejo e da clínica destes animais ainda é escasso e a mortalidade é elevada nos criatórios, tornando urgente a ampliação destes. Embora alguns estudos hematológicos já tenham sido realizados em cascavéis (Crotalus durissus) os dados analisados ainda são insipientes, notadamente em relação à caracterização das células do sangue e poucos estudos em microscopia eletrônica foram realizados em serpentes. Com o objetivo de caracterizar as células sanguíneas morfologicamente, sob microscopia óptica e ultraestrutural, foram coletadas amostras de sangue de 52 de indivíduos da subespécie Crotalus durissus terrificus para a realização de esfregaços sanguíneos e avaliação ultraestrutural. Concluiu-se que a coloração hematológica de Giemsa permite a avaliação morfológica e a diferenciação das células san- 
guíneas em serpentes assim como a visualização de hemoparasitos. A avaliação ultraestrutural permite evidenciar as organelas celulares e a diferenciação entre as células, inclusive entre os tipos leucocitários, porém ainda são necessários outros estudos para que seja elucidada a hipótese da existência dos eosinófilos na espécie estudada assim como é necessária melhor caracterização dos grânulos dos azurófilos para que se confirme uma possível diferença entre os monócitos típicos e os azurófilos.

TERMOS DE INDEXAÇÃO: Diagnóstico, hematologia, células sanguíneas, leucócitos, microscopia eletrônica, serpente.

\section{INTRODUÇÃO}

A avaliação hematológica tem importância comprovada no diagnóstico de doenças de pequenos animais domésticos e vem se tornando comum em animais selvagens não apenas para a clínica, mas para a avaliação do manejo e como estudo auxiliar para a fisiologia das várias espécies (Frye 1991, Almosny \& Santos 2000). 0 aumento da extração de veneno visando a produção de soro antiofídico, que teve a demanda bastante elevada segundo dados do Instituto Vital Brazil (2011), e de várias drogas de importância farmacêutica vem modificando a visão a respeito da criação de serpentes. Assim, antes criadas para a produção de soro anti-ofídico (Araújo et al. 2003, Brasil 2007), as serpentes peçonhentas passaram a ser reconhecidas como sendo animais de produção. 0 conhecimento do manejo e da clínica destes animais ainda é escasso e a mortalidade é elevada nos criatórios, tornando urgente a sua ampliação. Para que isto ocorra, além do conhecimento da biologia da espécie, a fim de permitir uma maior sobrevida do animal, há uma necessidade crescente da avaliação do estado de saúde das serpentes para a manutenção de indivíduos saudáveis. Com isso, o conhecimento do manejo e da clínica destes animais se torna prioritário.

Considerado como exame de triagem clínica, o hemograma vem sendo utilizado no auxílio ao diagnóstico, no acompanhamento clínico e no prognóstico de diversas moléstias que acometem diferentes espécies de animais (Almosny \& Santos 2000, Silva et al. 2009). Com o crescimento da importância da medicina de animais selvagens os exames hematológicos passaram a auxiliar não apenas no diagnóstico, mas também como biomarcadores de manejo inadequado e de poluição ambiental. As diferenças morfológicas observadas nas células sanguíneas de aves, répteis, anfíbios e peixes tornaram necessárias adaptações nas técnicas utilizadas em animais domésticos, notadamente pelo fato destes apresentarem eritrócitos nucleados e trombócitos, o que inviabilizaria os métodos anteriormente usados (Almosny 2014). Apesar de existirem alguns estudos referentes à citoquímica e à microscopia eletrônica das células sanguíneas de alguns animais selvagens estes dados analisados isoladamente ainda são insipientes para caracterizar um perfil que sugira a função dos diferentes tipos leucocitários no organismo destes animais.

A caracterização morfológica das células do sangue de répteis tem como base as suas características em colorações do tipo Romanowsky e as características das células dos mamíferos domésticos vêm sendo o padrão utilizado como comparativo para as diferentes espécies de répteis, mas são observadas diferenças entre elas que precisam ser melhor compreendidas. Contudo, apesar de existirem trabalhos referentes à hematologia de répteis desde décadas passadas, relativamente pouco se sabe a respeito da hematologia de indivíduos da ordem Squamata.

Para algumas espécies comumente criadas em cativeiro, como as "cascavéis", são encontrados relatos referentes à hematologia (Freitas et al. 2003, Silva et al. 2010). Entretanto, para a ordem Squamata e também para C. durissus, existem vários questionamentos ainda não elucidados como a hipótese da não existência de eosinófilos (Montali 1988, Dotson et al. 1995) ou a existência da célula em somente alguns membros da ordem (Hawkey \& Dennet 1994, Campbell 1996). É possível que a microscopia eletrônica possa trazer evidências concretas que elucidem esse problema, ampliem o conhecimento sobre a ultraestrutura das células sanguíneas e, consequentemente, do mecanismo das respostas celulares possibilitarão melhores condições no manejo veterinário dos plantéis. Sendo assim, o objetivo do presente estudo foi caracterizar, morfologicamente e ultraestruturalmente, as células sanguíneas pertencentes a subespécie Crotalus durissus terrificus.

\section{MATERIAL E MÉTODOS}

O presente trabalho foi submetido e aprovado pelo Comitê de Ética em Pesquisa Animal (CEPA) da Universidade Federal Fluminense (no 92/11), por estar de acordo com os Princípios Éticos na Experimentação Animal do Comitê de Ética em Bem-Estar Animal (COBEA).

Foram utilizados no trabalho 52 animais da espécie Crotalus durissus pertencentes ao serpentário do Instituto Vital Brazil, situado na cidade de Niterói, Rio de Janeiro, com o intuito de caracterizar as células sanguíneas sob microscopia óptica e microscopia eletrônica de transmissão.

Os animais foram capturados em seus recintos sendo contidos, apenas, fisicamente utilizando-se um tubo transparente e um gancho herpetológico (McDonald 1976). Após a contenção do animal, o sangue foi obtido por punção da veia coccígea, segundo Campbell (2004), Mader (2006), Almosny \& Monteiro (2006) e Almosny (2014) utilizando seringas de 1,0 mL e agulhas 20 x 5,5 estéreis e o material obtido foi acondicionado e tubos cônicos de $2,0 \mathrm{ml}$ rinsados com heparina sódica $5000 \mathrm{UI}$. Em cada coleta, foi obtido cerca de 0,8-1,0 mL de sangue de cada animal durante todo o período do trabalho obedecendo ao estabelecido pela literatura em observância ao peso dos animais utilizados (Lillywhite et al. 1983, Jacobson 1993, Campbell 1996a, 2004, 2006, Mader 2006).

No momento da obtenção das amostras de sangue foram confeccionados esfregaços sanguíneos sem anticoagulante para realização da leucometria específica, hematoscopia, pesquisa de hemoparasitos. Os esfregaços confeccionados foram corados com Giemsa (Merck ${ }^{\circledR}$ ), descrito por Silva et al. (2009) como sendo o corante de melhor qualidade para a visualização das células sanguíneas de serpentes. Para estudos posteriores visando padronização de índices eritrocitários foram realizadas diluições de sangue total e contagem em câmara de Neubauer ${ }^{\circledR}$ (Improved) conforme Almosny \& Monteiro (2006).

As amostras de sangue das serpentes foram examinadas em microscopia óptica de imersão e em microscopia eletrônica de transmissão quando foram evidenciadas as características morfológicas e ultraestruturais de cada célula, e efetuou-se a contagem diferencial. 
Métodos em microscopia óptica. Depois de corados, os esfregaços foram lidos em microscopia óptica em aumento de 1000x utilizando-se óleo de imersão . Foi avaliada a morfologia de todos os tipos celulares, eritrócitos, trombócitos e leucócitos. Os tipos de leucócitos que foram descritos estão de acordo com a morfologia e a classificação proposta por Hawkey \& Dennet (1994) que os classificaram em células mononucleadas (linfócitos, monócitos e azurófilos) e granulócitos (heterófilos e basófilos).

Embora haja o consenso de que azurófilos sejam monócitos (Campbell \& Ellis 2007), devido a diferenças citoquímicas citadas na literatura, estas células foram identificadas como sendo diferentes, seguindo o mesmo critério adotado por outros autores (Troiano et al. 1997, Santos 2005, Almosny \& Monteiro 2006, Strick et al. 2007). Os leucócitos contados foram diferenciados em basófilos, heterófilos, azurófilos, linfócitos e monócitos, e uma contagem paralela de trombócitos foi realizada no esfregaço corado conforme descrito por Troiano et al. (1997) e Almosny \& Monteiro (2006).

Métodos em microscopia eletrônica de transmissão. Foi coletado 1,0 mL de sangue através da veia caudal, usando-se o anticoagulante EDTA (ácido etilenodiamino tetra-acético). A partir desta amostra, os leucócitos foram separados segundo metodologia descrita por DaMatta et al. $(1998,1999)$ para sangue de aves.
Em seguida, as amostras foram preparadas para a microscopia eletrônica de transmissão.

Técnica de rotina para observação de ultraestruturas celulares. Após centrifugação do material coletado as células foram colocadas por 2 horas em solução fixadora contendo glutaraldeído 2,5\%, formaldeído nascente $4 \%$, cloreto de cálcio $5 \mathrm{mM}$ em tampão PHEM (PIPES 60mM, HEPES 20mM, EGTA 10mM, KCL 70mM, MgCL2 5mM), pH 7,2, conforme Tripp (1970). Ao retirar o fixador, foram realizadas três lavagens por 10 minutos cada, em tampão cacodilato $0,1 \mathrm{M}$ e pH 7,2. Para melhor preservação das estruturas celulares foi feito a pós-fixação em solução e tetróxido de ósmio a 1\%, contendo ferrocianeto de potássio 0,8\%, $5 \mathrm{mM}$ de cloreto de cálcio em tampão cacodilato $0,1 \mathrm{M} \mathrm{e} \mathrm{pH} \mathrm{7,2} \mathrm{por} 60 \mathrm{mi}$ nutos a $4^{\circ} \mathrm{C}$ e em ausência de luz. Para retirar o tetróxido de ósmio e demais substâncias, foram feitas três lavagens por 10 minutos cada em tampão cacodilato $0,1 \mathrm{M}$ e pH 7,2 contendo $5 \%$ de sacarose. A etapa de diafanização em bloco foi realizada por $60 \mathrm{minu}-$ tos, em temperatura ambiente e na ausência de luz com acetato de uranila a 2,5\% diluída em acetona a $25 \%$. Para a desidratação foi usada uma bateria de acetona com passagens do material em concentrações de $50 \%, 70 \%$ e $90 \%$ por 5 minutos em cada etapa, e depois acetona a $100 \%$, em 3 etapas de 5 minutos. Para a infiltração em resina foi usada uma mistura de Epon/acetona 100\%,

Fig.1. Eritrócitos de Crotalus durissus corados com coloração do tipo Romanosvky: (A) MGG, (B) Panótico rápido, (C) Wright e (D) Giemsa. (E) Eritrócitos binucleados e (F) processo de mitose. Barra $=10 \mu \mathrm{m}$.

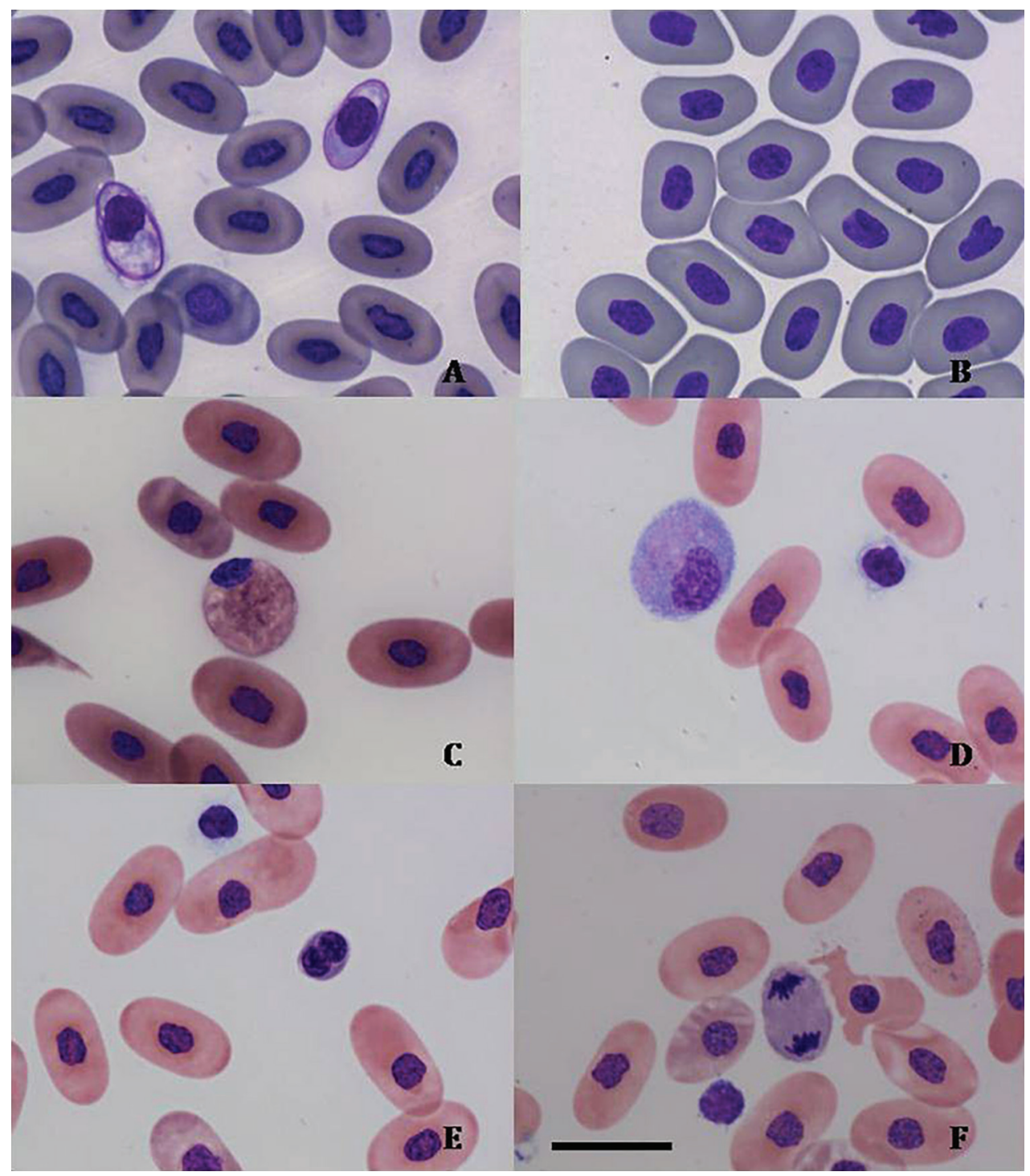


na proporção de 1:1 por 12 a 24 horas, seguida por 12 a 24 horas de infiltração em Epon puro. Para a inclusão celular foi usada Epon mais DMP-30 na estufa $60^{\circ} \mathrm{C}$ por 48 horas. Finalmente, os blocos contendo o material foram cortados em fatias com $70 \mathrm{~nm}$ de espessura e montados em grades (300 mesh). Esse material foi contrastado em acetato de uranila, lavado, e depois com citrato de chumbo, lavado novamente em água destilada, para finalmente ser examinado em MET ZEISS, $80 \mathrm{Kv}$. Os achados ultraestruturais foram obtidos no microscópio eletrônico de transmissão Carl Zeiss EM900.

\section{Microscopia óptica}

\section{RESULTADOS}

Na microscopia óptica, foram observados os esfregaços corados pelo método de Giemsa e realizou-se a contagem diferencial dos leucócitos, o diagnóstico de hemoparasitos e a caracterização morfológica das células sanguíneas.

\section{Hemácias}

As hemácias eram a maioria entre as células presentes no esfregaço sanguíneo. As hemácias maduras pouco variavam quanto ao formato apresentando-se ovais e alongadas com o citoplasma ocupando entre 70 a $80 \%$ da célula (Fig.1A-D). Os núcleos dos eritrócitos eram redondos, ovalados ou amebóides, com o seu contorno geralmente liso, apresentando cromatina densa de coloração que variava de azul marinho a roxo enegrecido e o seu formato acompanhava o do diâmetro maior da célula. Em algumas serpentes observou-se pleomorfismo nuclear e algumas hemácias apresentaram binucleação e outras estavam em processo de mitose (Fig.1E e F).

\section{Leucócitos}

Basófilos. Os basófilos apresentavam grande número de grânulos basofílicos no citoplasma, o que dificultava a visualização do núcleo, o tamanho destas células era variado. 0 aspecto "amora", descrito por Silva et al. (2009), foi caracterizado pela presença de grandes e numerosos grânulos de formato redondo no citoplasma de coloração intensamente basofílica.

Heterófilos. Nas amostras que foram estudadas, os heterófilos era redondo pequeno e excêntrico, possuindo coloração desde roxo à enegrecido e de contorno discretamente irregular, porém delimitado. Apresentavam grande variedade de grânulos pleomórficos em seu citoplasma, com formato que variava entre redondo a elíptico, de coloração rosa em diversos tons (Fig.2). Foi observado a ocorrência de degranulação citoplasmática nos esfregaços sanguíneos de alguns animais (Fig.3A,B e D,E).

\section{Monócitos}

Os monócitos típicos mostraram-se relativamente maiores que os linfócitos. Apresentavam um formato redondo à amebóide, o citoplasma era abundante e alguns estavam vacuolados. 0 citoplasma corou-se em tonalidade azul levemente acinzentado, porém bem marcante, com presença de finos grânulos de tonalidade azurofílica. Os núcleos eram discretamente pleomórficos e a cromatina, menos condensada, se corava menos intensamente que os linfócitos (Fig.4).

\section{Azurófilos}

Apresentavam-se como células mononucleares arredondadas. Os citoplasmas, de tonalidade azul, apresentavam grande quantidade de finos e delicados grânulos de coloração rosa a lilás intenso conferindo um padrão de coloração que variava irregularmente de azul a rosa (Fig.5A,B e D).

A presença de vacúolos pode ser observada na maioria das células presentes (Fig.5C) e estes variavam tanto em tamanho quanto em quantidade. 0 núcleo era excêntrico, formado por um padrão de cromatina densa e de coloração basofílica com tonalidade de roxo escuro.

Linfócitos. Os linfócitos apresentaram-se, em sua maioria, como células pequenas que mediam cerca de $1 / 3$ do tamanho de uma hemácia normal e tinham o formato, predominantemente, arredondado. 0 citoplasma fino se corou, suavemente, em tom basofílico, na cor de cinza-azulado (Fig.6A,B,C e D). Foi observada a presença de grânulos azurofílicos e basofílicos em alguns linfócitos. Estes grânulos estavam dispostos no citoplasma e variavam desde alguns poucos até numerosos que chegavam a encobrir todo o citoplasma (Fig.6E,F).

\section{Trombócitos}

O formato dos trombócitos variava de elíptico-alongado até ameboide. As dimensões deste tipo celular não variaram muito apresentando-se, em média, com um terço do tamanho das hemácias. Os citoplasmas eram transparentes à levemente eosinofílicos. 0 formato dos núcleos variava de

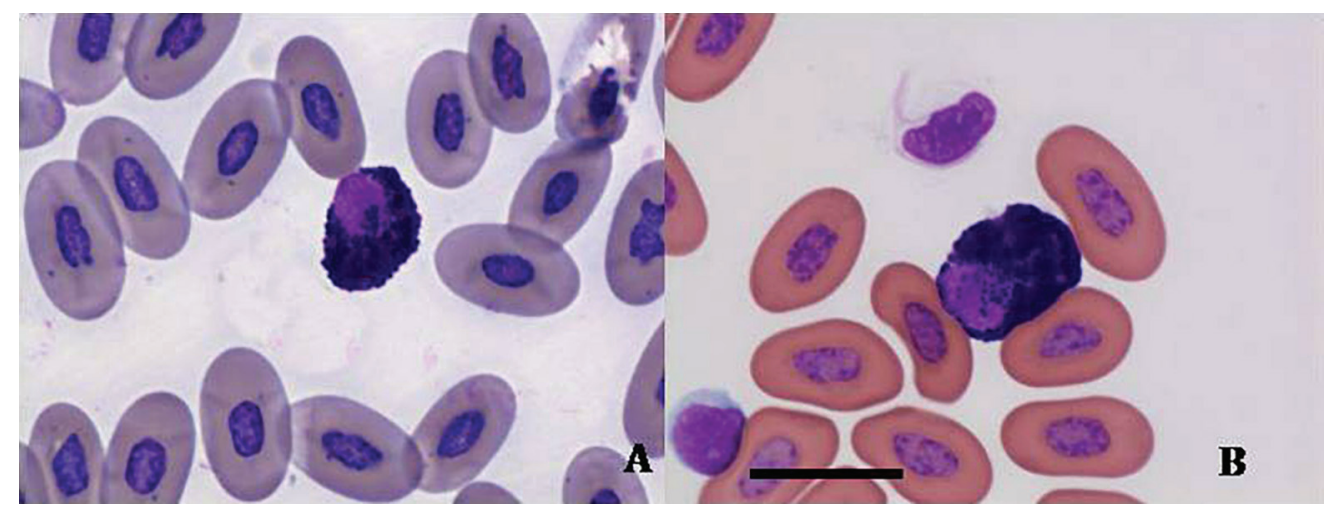

Fig.2. Basófilos de Crotalus durissus com presença de grânulos de coloração basofílica intensa, demonstrando aspecto de "amora". (A) Coloração de MGG e (B) de Wright. Barra = $10 \mu \mathrm{m}$. 


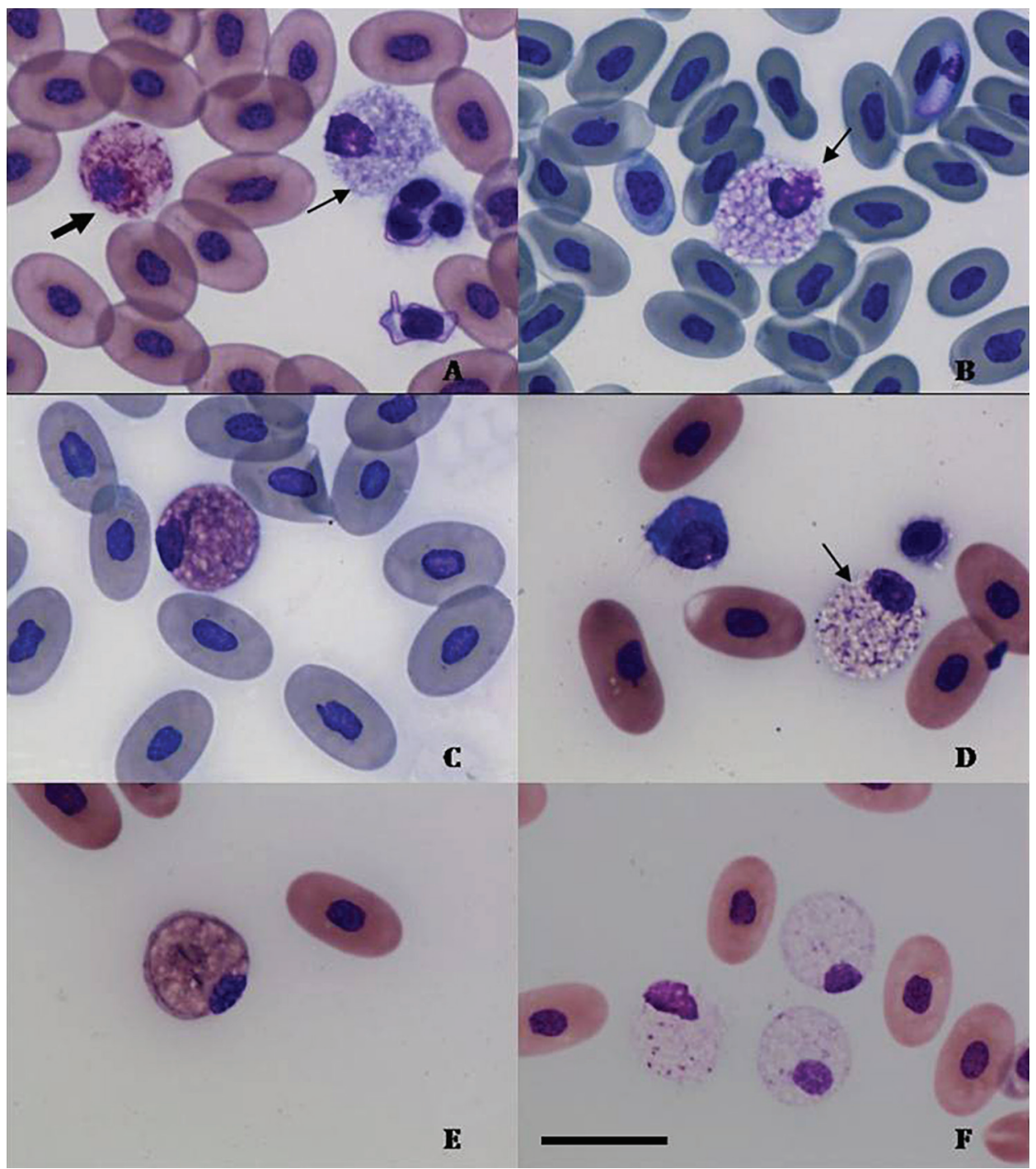

Fig.3. (A) Heterófilo degranulado de Crotalus durissus apresentando grânulos citoplasmáticos finos e coloração escura a hialina (seta fina) e heterófilo íntegro (seta espessa), corados com MGG. (B) Heterófilo degranulado corado com Panótico rápido (seta) e (C) íntegro. (D) Heterófilo degranulado corado com Wright (seta) e (E) íntegro. (F) Heterófilos degranulados corados com Giemsa. Barra = 10 $\mu$ m.

redondo a oval com contorno liso ou irregular e cromatina densa com aspecto enegrecido (Fig.7A,B,C). Foi observada a presença de trombócitos em divisão nuclear e, também, ativados (Fig.7D), quando se agregavam uns aos outros.

\section{Microscopia eletrônica de transmissão}

Não foram encontrados, na literatura, trabalhos que relatem a ultraestrutura de células sanguíneas de $C$. durissus, porém já foram realizados trabalhos em espécies diferentes de aves e répteis.

\section{Leucócitos}

Basófilos. Em microscopia eletrônica de transmissão os núcleos dos basófilos eram periféricos com abundância de áreas preenchidas por eucromatina. Estas células apresentaram grânulos difusos pelo citoplasma de formato arredondado e elétron-densos que se diferenciam dos heterófilos por serem granulações menores e mais elétron-densas (Fig.8D).

Heterófilos. Os heterófilos apresentaram núcleos excêntricos com presença de heterocromatina periférica e escassa no centro. A eucromatina estava presente em abundância na região central chegando a avançar rumo à periferia nuclear, onde por vezes se observa apenas uma pequena região de heterocromatina. Os grânulos apresentavam formato variavam entre arredondados e de clave ou fusiforme, característico deste tipo leucocitário. (Fig.9 C e D). Essas características também foram observadas em algumas aves, como os avestruzes, por Bonadimam et al. (2009).

\section{Monócitos}

Os monócitos apresentaram os núcleos, predominantemente, excêntricos de formato riniforme ou arredondado, heterocromatina periférica e abundância de eucromatina justificando a sua atividade fagocítica (Fig.8B). No citoplasma, vacúolos foram observados com frequência, além da presença de um grande número de mitocôndrias. Este padrão mitocondrial é o mesmo nas mais variadas espécies. Não foram observadas evidências sugestivas de azurófilos (Fig.9A,B). 


\section{Linfócitos}

Os linfócitos apresentaram núcleo centralizado típico com heterocromatina distribuída em sua periferia (Fig.8C), com a presença de eucromatina abundante na região central, que eventualmente era preenchida por escassa heterocromatina. 0 citoplasma apresentou-se homogêneo e escasso (Fig.10A,B), com relativamente poucas organelas.

\section{Eosinófilos}

Não foram observadas evidências sugestivas de eosinófilos no material examinado.

\section{Trombócitos}

Os trombócitos apresentaram núcleo polimórfico que mostravam abundante e densa heterocromatina periferica. Também foram visualizados alguns vacúolos citoplas-

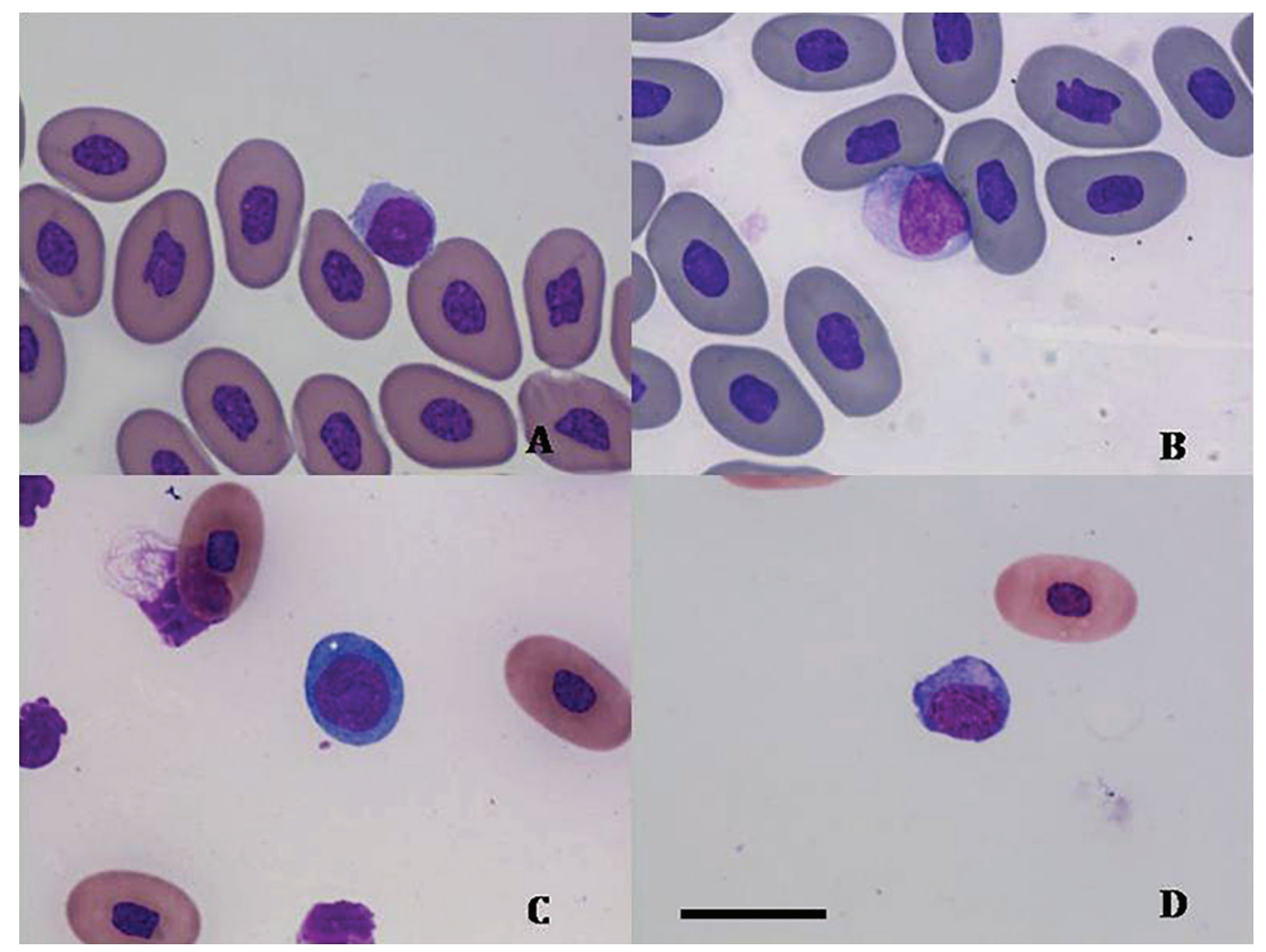

Fig.4. (A) Monócitos de Crotalus durissus corados com MGG, (B) Panótico rápido, (C) Wright, (D) Giemsa, observa-se que o núcleo se apresenta pleomórfico. Barra = $10 \mu \mathrm{m}$.

Fig.5. (A) Azurófilos de Crotalus durissus corados com MGG, (B) Panótico rápido, (C) Wright com presença de vacúolos citoplasmáticos (seta), (D) Giemsa. Barra = $10 \mu \mathrm{m}$.

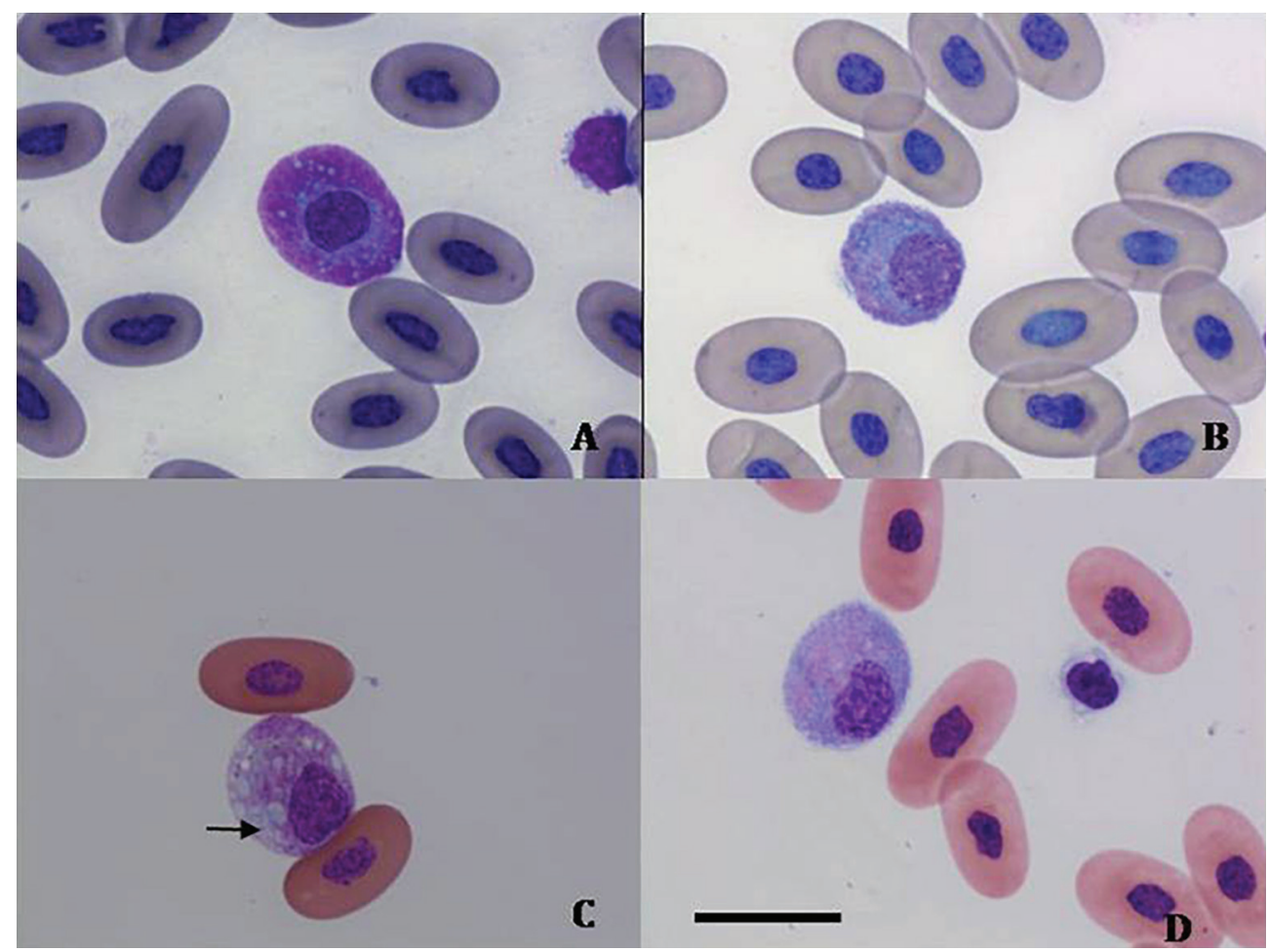




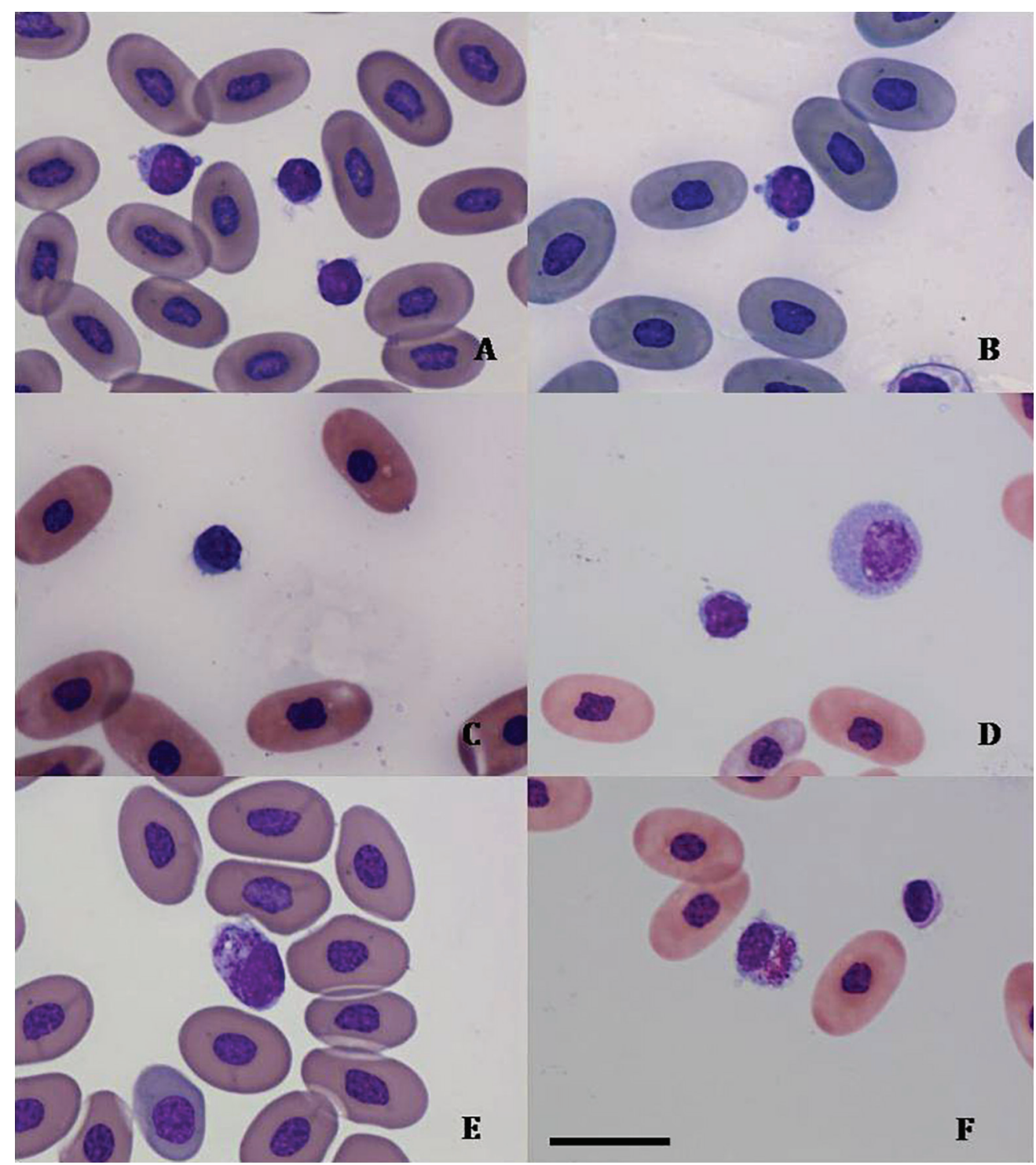

Fig.6. (A) Linfócito de Crotalus durissus corados com MGG, (B) linfócito com "blebs" corado com Panótico rápido, (C) Wright, (D) Giemsa. (E) Linfócito corado com MGG e (F) linfócito apresentando grânulos basofílicos e eosinofílicos dispersos por todo o citoplasma, corado com Giemsa. Barra $=10 \mu \mathrm{m}$.

máticos não visualizados na microscopia óptica (Fig.8A). Foi observado o sistema canalicular que se comunica à invaginações da membrana plasmática. Através desde sistema o citosol do trombócito comunica-se com o meio extracelular, o que facilita a liberação de moléculas que estão armazenadas. Segundo Casal et al. (2007), este sistema canalicular é característico desta célula (Fig.10C,D). Foi, frequentemente, observado material dentro de vacúolos citoplasmáticos que segundo DaMatta et al. (1998) é, possivelmente, material fagocitado, (Fig.10E). Os trombócitos foram observados, frequentemente, em agregados.

\section{DISCUSSÃO}

Na microscopia óptica, as características morfológicas em eritrócitos de serpentes, foram as mesmas já relatadas por Frye (1991), Campbell (1996b) em répteis e por Silva et al. (2010), especificamente, em C. durissus. 0 pleomorfis- mo nuclear observado pode ser sugestivo de inflamação. Entretanto, a binucleação observada em algumas destas células, pode não estar relacionada a processos patológicos, como em mamíferos, uma vez que a hematopoiese de serpentes se completa na circulação sanguínea (Silva et al. 2010). No presente estudo observou-se que dois animais apresentaram binucleação eritrocitária, mas não anemia, e em um deles observou-se hemácia em processo de mitose. Eritrócitos jovens também foram observados. Eram células de tamanho menor que de um eritrócito maduro e a coloração do citoplasma, basofílica, não era homogênea. Estas características também foram relatadas por Silva et al. (2010). Os eritrócitos jovens, geralmente, eram mais frequentes em animais parasitados por Hepatozoon sp. e Plasmodium sp. No estudo atual, dez (10) dos cinquenta e dois (52) espécimes avaliados estavam parasitados por hemoparasitas do gênero Hepatozoon e outros dois pelo gênero Plasmodium. 0 parasito do gênero Plasmodium 


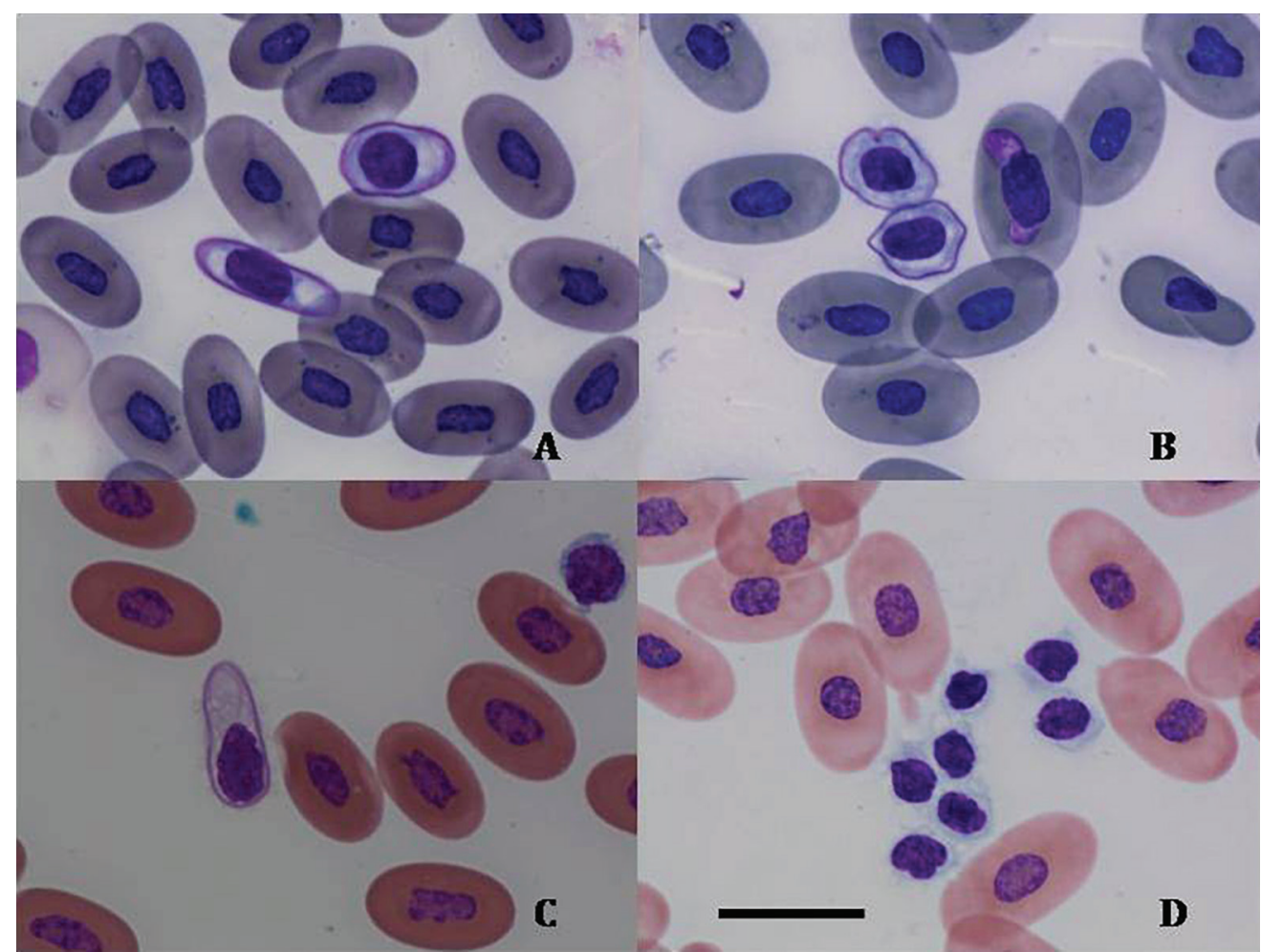

Fig.7. (A) Trombócitos de Crotalus durissus corados com MGG, (B) Panótico rápido, (C) Wright, (D) agregado trombocitário, demonstrando trombócitos ativados corados com Giemsa. Barra $=10 \mu \mathrm{m}$.

foi confirmado pelo método de polarização em que seu pigmento apresentou birrefringência (De Macchi et al. 2013).

Embora protozoários do gênero Hepatozoon seja frequentemente observado em esfregaços sanguíneos de serpentes acredita-se que em condições de estresse eles possam acarretar anemias de intensidade variável (Almosny 2014).

Embora a literatura venha relatando que os basófilos de serpentes são células pequenas, como em B. leucurus (Grego et al. 2006) e em C. durissus (Silva et al. 2009), no estudo atual, observou-se basófilos grandes e pequenos. Na microscopia eletrônica de transmissão os achados foram similares aos encontrados por Carvalho \& Egami (2006) em teiú-gigante (Tupinambis merianae) e por Zago et al. (2010) em cágado de barbicha (Phrynops geoffroanus).

As características morfológicas, observadas nos heterófilos do estudo atual foram as mesmas já descritas anteriormente por Almosny \& Santos (2000), Campbell (2004) em répteis e por Silva et al. (2010) em seus estudos com serpentes. Tem sido observado, que a ocorrência de degranulação está associada, normalmente, a processos inflamatórios no animal (Silva et al. 2009, Almosny \& Santos 2000). Observou-se, no presente trabalho, que alguns heterófilos apresentavam grânulos citoplasmáticos diferenciados, finos e de coloração escura a hialina, o que também foi relatado por Silva et al. (2010). A partir de estudos citoquímicos e ultraestruturais, verificou-se que os heterófilos são semelhantes aos neutrófilos de mamíferos, participando do processo de fagocitose das bactérias e material estranho. Eles desempenham um papel importante na imunidade inata e de res- posta a vários estímulos inflamatórios, que foi demonstrado em estudo realizado com tartarugas conhecidas como tigre d'água (Chrysemys dorbignih) por Azevedo \& Lunardi (2003). Embora apresentem morfologia nuclear distinta, os heterófilos de $C$. durissus eram semelhantes aos observados em outras espécies, como em teiú-gigante (Tupinambis merianae) por Carvalho \& Egami (2006), em avestruz (Struthio camelus), por Bonadimam et al. (2009) e em cágado de barbicha (Phrynops geoffroanus), por Zago et al. (2010) em. Em microscopia eletrônica de transmissão foram observados dois tipos de grânulos citoplasmáticos diferentes, que apresentavam elétron-densidades diferentes, além de variarem na forma e no tamanho, conforme também observado por Bonadimam et al. (2009) e Zago et al. (2010).

Em microscopia optica os monócitos apresentavam características semelhantes aos descritos por Almosny \& Monteiro (2006) em répteis. Em microscopia eletrônica de transmissão a morfologia das estruturas observadas foram as mesmas já descritas em Phrynops geoffroanus, por Zago et al. (2010).

No presente estudo as características morfológicas presentes nos azurófilos, em microscopia optica, foram as mesmas já observadas por Silva et al. (2010). Trabalhos recentes demonstraram atuação decisiva dos azurófilos em processos infecciosos crônicos de serpentes, com atividade compatível com monócito, conforme relatado por Almosny \& Monteiro (2006). Segundo Silva et al. (2010), colorações citoquímicas, entretanto, mostram semelhanças bioquímicas com neutrófilos. Atualmente existe um consenso em considerar estas células como monócitos (Almosny \& Monteiro 2006). Não foi possível determinar a presença 


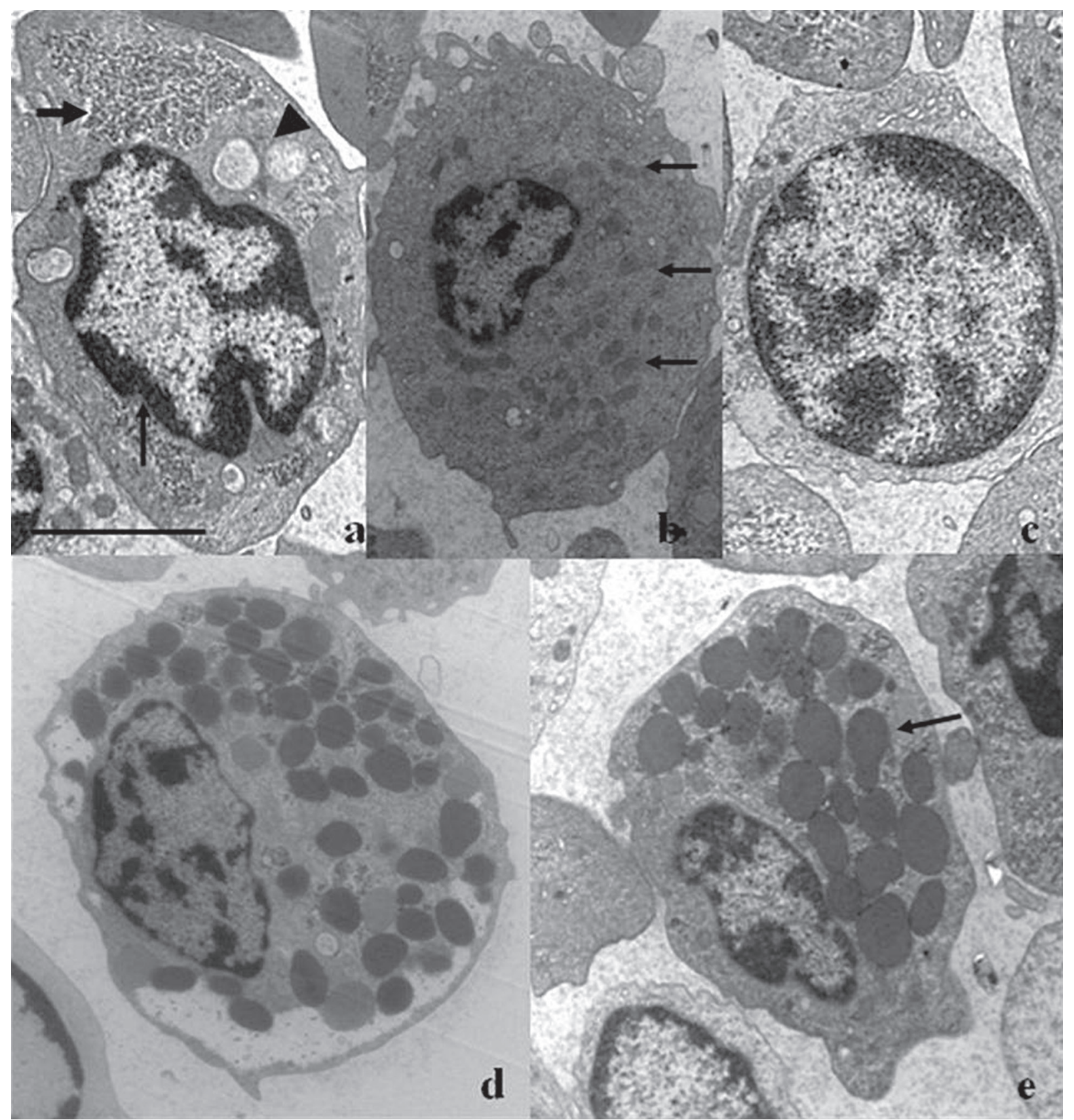

Fig.8. Trombócito e leucócitos de Crotalus durissus preparados para rotina em microscopia eletrônica de transmissão: (A) Trombócito apresentando núcleo repleto de heterocromatina (seta), presença de vacúolos citoplasmáticos (cabeça de seta), material fagocitado (seta larga). (B) Monócito, apresentando núcleo riniforme e citoplasma contendo grande número de mitocôndrias (setas). (C) Linfócito apresentando núcleo com heterocromatina, e citoplasma homogêneo e escasso. (D) Basófilo, apresentando grânulos difusos pelo citoplasma, porém menores que os observados nos heterófilos. (E) Heterófilo: presença de grânulos citoplasmáticos em diversos tamanhos e formas. Destaca-se grânulo característico em forma de clave (seta). Barra $=1 \mu \mathrm{m}$.

de azurófilos, com os estudos de microscopia eletrônica de transmissão, realizados no presente trabalho. Este fato, entretanto, pode ter ocorrido por se tratarem de animais clinicamente saudáveis quando o numero destas células são raras (Almosny 2014).

As características morfológicas dos linfócitos observados no estudo atual eram as mesmas que foram relatadas por Rodrigues (2000) para os gêneros Bothrops e Crotalus. Os achados de ultraestrutura encontrados no estudo atual, foram também já descritos em tartaruga cabeçuda (Caretta caretta), por Casal et al. (2007) e em cágado de barbicha por Zago et al. (2010).

Os trombócitos foram, facilmente, diferenciados dos linfócitos e foram observadas, nestas células, as mesmas características morfológicas descritas por Silva et al. (2010). Observou-se, ainda, que a cromatina nuclear de trombócitos é mais densa e uniforme do que a dos linfócitos como, também, descrito por Raskin (2000). Ultraestruturalmente, as características nucleares de polimorfismo e de heterocromatina abundante e densa na periferia, foi observada 


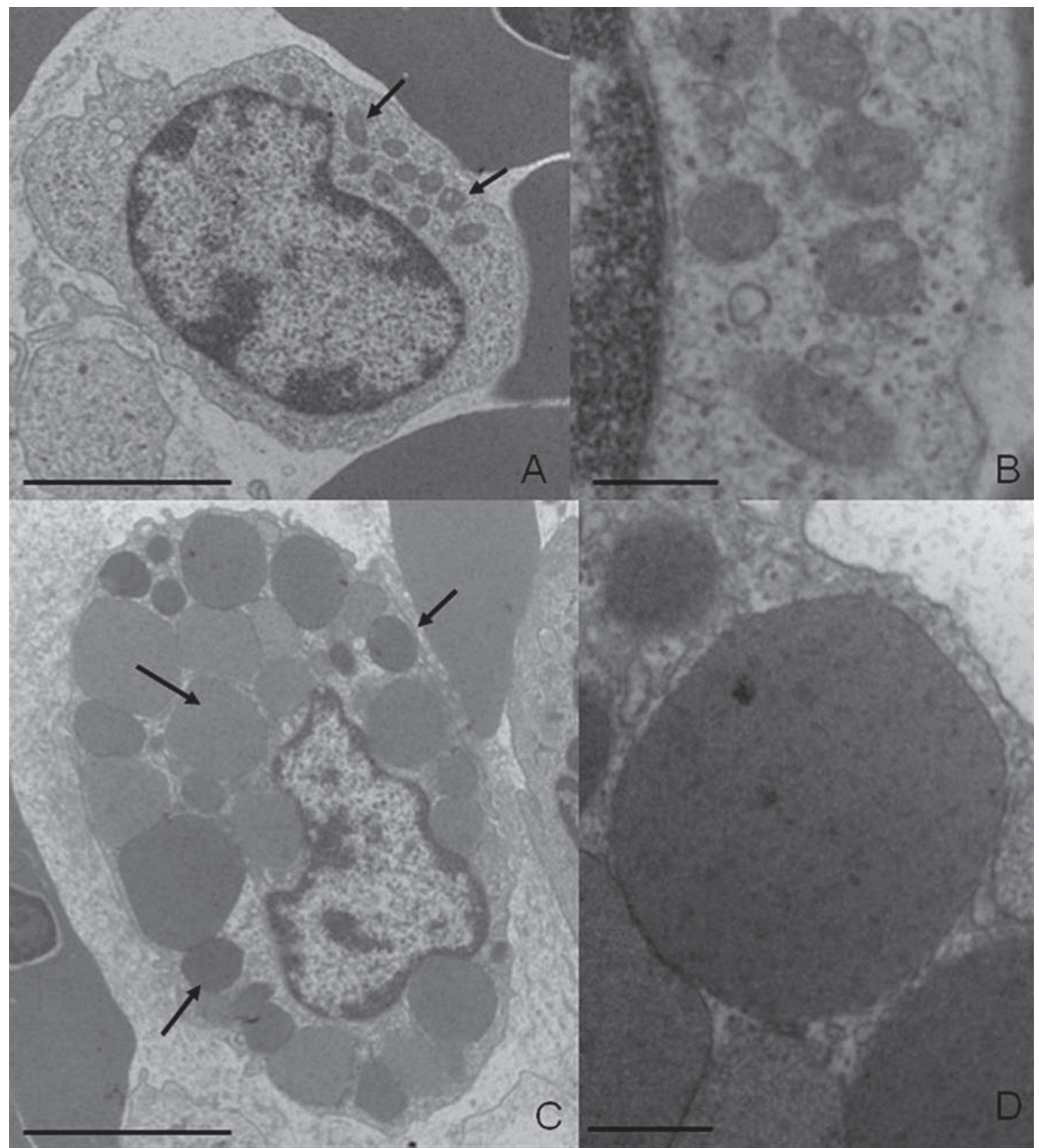

Fig.9. (A) Monócito. Pode ser observado um padrão mitocondrial típico (setas) desta linhagem celular (Barra = $1 \mu \mathrm{m}$ ), podendo ser observado em maior aumento em B (Barra $=200 \mu \mathrm{m})$. (C) Heterófilo. Note grande quantidade de grânulos citoplasmáticos, de variável

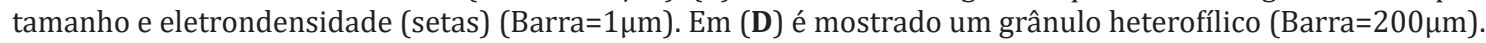

também por Alleman et al. (1999) em estudos com Crotallus adamanteus e Zago et al. (2010) com Phrynops geoffroanus. Os trombócitos, frequentemente, apresentaram grande quantidade de material fagocitado em seu interior quando observados pela microscopia eletrônica de transmissão conforme também foi relatado por DaMatta et al. (1998).

\section{CONCLUSÕES}

A partir dos resultados obtidos, concluiu-se que a coloração hematológica de Giemsa permite a avaliação morfo- lógica e a diferenciação das células sanguíneas em serpentes assim como a visualização de hemoparasitos.

A avaliação ultraestrutural evidencia as organelas celulares e, em consequência, melhor diferenciação entre os tipos leucocitários.

Não foi possível a observação e caracterização do eosinófilo, sendo necessários mais estudos a respeito deste leucócito nas serpentes assim como é necessária melhor caracterização dos grânulos dos azurófilos para que se confirme uma possível diferença entre os monócitos típicos e os azurófilos. 


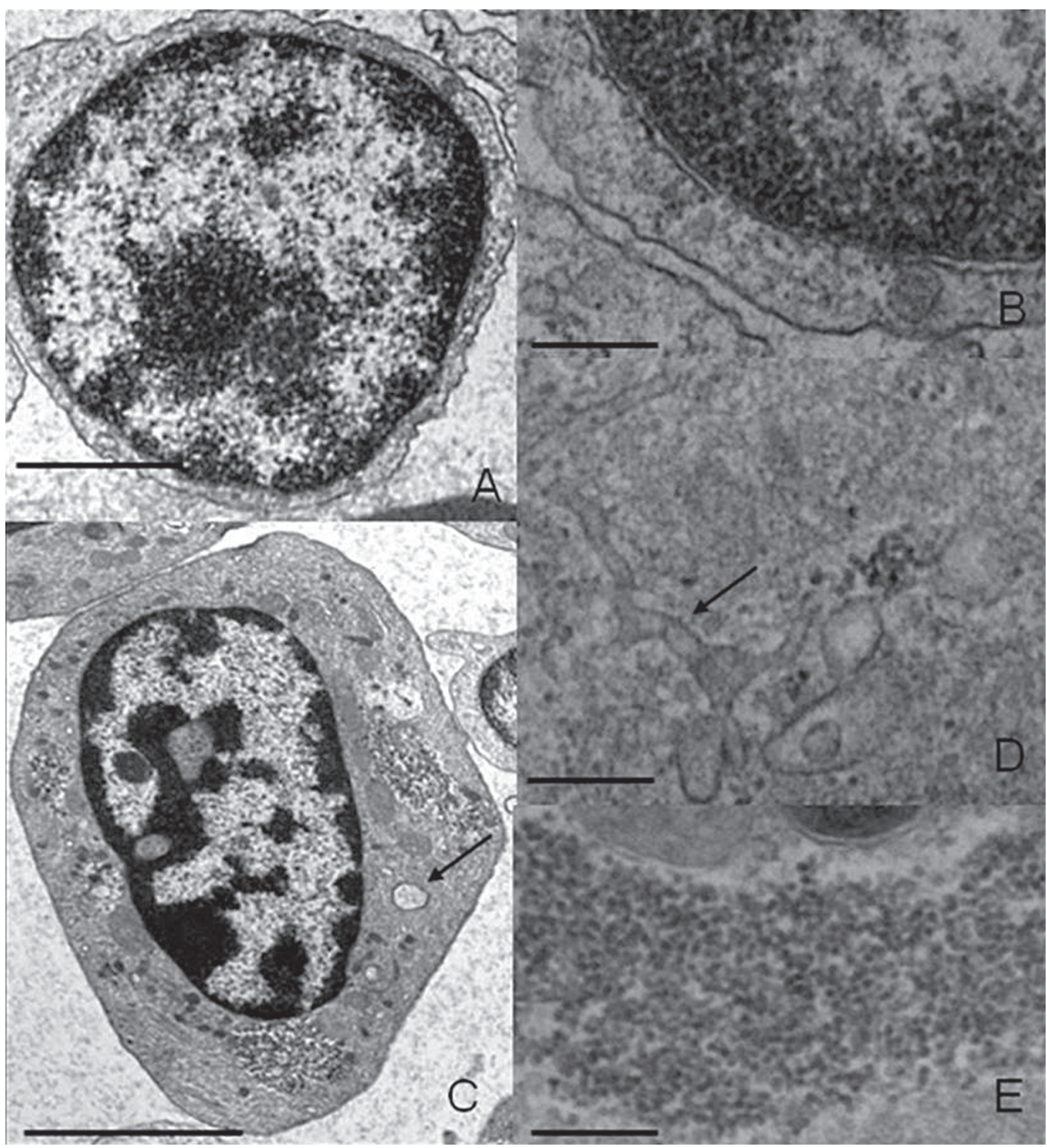

Fig.10. (A) Linfócito apresentando núcleo com heterocromatina e citoplasma homogêneo e escasso (Barra=1 $\mu \mathrm{m})$, pode se observar em maior detalhamento em B (Barra= $200 \mu \mathrm{m})$. (C) Trombócito, apresentando núcleo repleto de heterocromatina $($ Barra $=1 \mu \mathrm{m})$ com presença de vacúolos citoplasmáticos (seta); sistema canalicular interno (seta) em D (Barra = 200 $\mu$ m). Material fagocitado em E.

Agradecimentos.- Ao Cláudio Machado, chefe da Divisão de Herpetologia do Instituto Vital Brazil, por ceder os animais para aquisição das amostras de sangue. À Coordenação de Aperfeiçoamento de Pessoal de Nível Superior (CAPES).

\section{REFERÊNCIAS}

Alleman A.R., Jacobson E.R. \& Raskin R.E. 1999. Morphologic, cytochemical staining, and ultrastructural characteristics of blood cells eastern diamondback rattlesnakes (Crotalus adamanteus). Am. J. Vet. Res. 60(4): 507-14.

Almosny N.R.P. \& Santos L.C. 2000. Laboratory in wild animals, p.300-320. In: Fowler M. (Ed.), Biology, Medicine and Surgery of South American Wild Animals. Editora Iowa State University, Ames.

Almosny N.R.P. \& Monteiro A.M. 2006. Patologia clínica, p.939-966. In:
Cubas Z.S., Silva J.C.S. \& Catão-Dias J.L. (Eds), Tratado de Animais Selvagens: medicina veterinária. Roca, São Paulo.

Almosny N.R.P. 2014. Patologia clínica em vertebrados ectotérmicos, p.1597-1623. In: Cubas Z.S., Silva J.C.S. \& Catão-Dias J.L. (Eds), Tratado de Animais Selvagens: medicina veterinária. 2ª ed. Roca, São Paulo.

Araújo F.A.A., Santalúcia M. \& Cabral R.F. 2003. Epidemiologia dos acidentes por animais peçonhentos, p.6-12. In: Cardoso J.L.C. (Ed.), Animais Peçonhentos no Brasil: biologia, clínica e terapêutica dos acidentes. Sarvier, São Paulo.

Azevedo A. \& Lunardi L.O. 2003. Cytochemical characterization of eosinophilic leukocytes circulating in the blood of the turtle (Chrysemys dorbignih). Acta Histochimica 105(1):99-105.

Bonadimam S.F., Stratievsky G.C., Machado J.A., Albernaz A.P., Rabelo G.R. \& Damatta R.A. 2009. Leukocyte ultrastructure, hematological and 
serum biochemical profiles of ostriches (Struthio camelus). Poult. Sci. 88:2298-2306.

Brasil 2007. Programa Nacional de Ofidismo. Ministério da Saúde. Disponível em <http://www.saude.gov.br> Acesso em 20 fev. 2007.

Campbell T.W. 1996a. Clinical pathology, p.248-257. In: Mader D.R. (Ed.), Reptile Medicine and Surgery. W.B. Saunders, Philadelphia.

Campbell T.W. 1996b. Hemoparasites, p.379-381. In: Mader D.R. (Ed.), Reptile Medicine and Surgery. W.B. Saunders, Philadelphia.

Campbell T.W. 2004. Hematology of reptiles, p.259-276. In: Thrall M.A., Baker D.C., Campbell T.W., DeNicola D.B., Fettman M.J., Lassen E.D., Rebar A. \& Weiser G. (Eds), Veterinary Hematology and Clinical Chemistry. Lippincott Williams and Wilkins, Baltimore.

Campbell T.W. 2006. Clinical pathology of reptiles, p.490-532. In: Mader D.R. (Ed.), Reptile Medicine and Surgery. Saunders Elsevier, Missouri.

Campbell T.W. \& Ellis C. 2007. Hematology of reptiles, p.51-82. In: Ibid. (Eds), Avian and Exotic Animal Hematology and Citology. 3rd ed. Blackwell, Ames.

Carvalho R.L. \& Egami M.I. 2006. Morphological, cytochemical, and ultrastructural observations on the blood cells of the reptile Tupinambis merianae (squamata). Comp. Clin. Pathol. 15:169-174.

Casal A.B., Freire F., Bautista-Harris G., Arencibia A. \& Orós J. 2007. Ultrastructural characteristics of blood cells of juvenile loggerhead sea turtles (Caretta caretta). Anat. Histol. Embryol. 36:332-335.

DaMatta R.A., Seabra S.H. \& De Souza W.J. 1998. Further studies on the phagocytic capacity of chicken thrombocytes. Submicrosc. Cytol. Pathol. 30(2):271-277.

DaMatta R.A., Manhães D.S.L., Seabra S.H. \& De Souza W. 1998. Coculture of chicken thrombocytes and monocytes: morphological changes and lectin binding. Biocell 22:45-52.

DaMatta R.A., Manhães D.S.L., Lassounskaiac E. \& Souza W. 1999. Chicken thrombocytes in culture: lymphocyte conditioned medium delays apoptosis. Tissues \& Cell 31(3):255-263.

De Macchi B.M., Mirandal F.J.B., Souza F.S., Carvalho E.C.Q., Albernaz A.P., Nascimento J.L.M. \& DaMatta R.A. 2013. Chickens treated with a nitric oxide inhibitor became more resistant to Plasmodium gallinaceum infection due to reduced anemia, thrombocytopenia and inflammation. Vet. Res. 44:1-8.

Dotson T.K., Ramsay E.C. \& Bounous D.I. 1995. A color atlas of the blood cells of the yellow rat snake. Compend. Contin. Educ. Pract. Vet. 17:10131016.

Freitas G., Grego K.F., Rameh-de-Albuquerque L. \& Zacariotti R.L. 2003. Hematological Reference intervals of recently-caught free-ranging South American rattlesnakes (Crotalus durissus terrificus Laurenti, 1768). Mem. Inst. Butantan 60:138-138.

Frye F.L. 1991. Hematology as applied to clinical reptile medicine, p.209277. In: Frye F.L. (Ed.), Reptile Care: an atlas of diseases and treatments. T.F.H. Publications, New Jersey.

Grego K.F., Alves J.A.S., Rameh de Albuquerque L.C. \& Fernandes W. 2006. Referências hematológicas para a jararaca de rabo branco (Bothrops leucurus) recém-capturadas da natureza. Arq. Bras. Med. Vet. Zootec. 58(6):1240-1243.
Jacobson E.R. 1993. Blood collection techniques in reptiles: laboratory instigations, p.144-151. In: Fowler M.E. (Ed.), Zoo and Wild Animal Medicine: current therapy. 3rd ed. W.B. Saunders, Philadelphia.

Hawkey C.M. \& Dennet T.B. 1994. A Color Atlas of Comparative Hematology. Wolfe Medical Publications, Ipswich, England.

Instituto Vital Brazil 2011. Disponível em <http://www.ivb.rj.gov.br> Acesso em 16 ago. 2011.

Lillywhite H.B., Ackerman R.A. \& Palacios L. 1983. Cardiorespiratory responses of snakes to experimental hemmorage. J. Comp. Physiol. 152: 59-65.

Mader D.R. 2006. Reptile Medicine and Surgery. W.B. Saunders, Philadelphia. 512p.

McDonald H.S. 1976. Methods for the physiological study of reptiles, p.19126. In: Gans C. (Ed.), Biology of Reptilia: physiology. Vol.5. Academic Press, New York.

Montali R.L. 1988. Comparative pathology of inflammation in the higher vertebrates (reptiles, birds, and mammals). J. Comp. Pathol. 99:1-26.

Raskin R.E. 2000. Reptilian complete blood count, p.193-204. In: Fudge A.M. (Ed.), Laboratory Medicine: avian and exotic pets. W.B. Saunders, Philadelphia.

Rodrigues L.M. 2000. Avaliação morfológica e citoquímica das células sanguíneas de serpentes dos gêneros Bothrops Wagler, 1824 e Crotalus Linnaeus, 1758. Dissertação de Mestrado em Clínica e Patologia Animal.Faculdade de Veterinária, Universidade Federal Fluminense, Niterói, RJ. 82p.

Santos K.R. 2005. Implicações do parasitismo por nematódeos do gênero Rhabdias (Nematoda, Rhabdiasidae) em Crotalus durissus terrificus (Serpentes, Viperidae): alterações pulmonares, microbiológicas e hematológicas. Dissertação de Mestrado em Medicina Veterinária. Faculdade de Medicina Veterinária e Zootecnia, Universidade Estadual Paulista Júlio de Mesquita Filho, Botucatu, SP.

Silva W.B., Machado C., Goldberg D.W., Moreira S.B., Silva L.C.C.P., Freire I.M.A., Maciel P.O. \& Almosny N.R.P. 2009. Avaliação da resposta inflamatória hematológica em cascavéis (Crotalus durissus Linnaeus, 1758) inoculadas com BCG. Pesq. Vet. Bras. 29:985-992.

Silva W.B., Soares R.M., Machado C., Freire I.M.A., Silva L.C.C.P., Moreira S.B., Goldberg D.M. \& Almosny N.R.P. 2010. Bioquímica plasmática de cascavéis (Caudisona durissa Linnaeus, 1758) em cativeiro. Ciência Rural 40:2510-2514.

Strick N.I., Alleman A.R. \& Harr K.E. 2007. Inflammatory cells, p.211-256. In: Jacobson E.R. (Ed.), Infection Disease and Pathology of Reptilies. CRC Press, Boca Raton.

Tripp M.R. 1970. Defense mechanisms of molluscs. J. Reticuloendothelial Society 7:173-182.

Troiano J.C., Vidal J.C., Gould J. \& Gould E. 1997. Haematological reference intervals of the South American rattlesnake (Crotalus durissus terrificus Laurent, 1768) in captivity. Comp. Haematol. Int. 1:109-112.

Zago C.E., Silva T.L., Silva M.I., Venancio L.P., Mendonça P.P., Falleiros Junior L.R., Vizotto L.D., Taboga S.R., Bonini-Domingos C.R., Azeredo-Oliveira M.T. \& Oliveira C. 2010. Morphological, morphometrical and ultrastructural characterization of Phrynops geoffroanus (Testudines:Chelidae) blood cells, in different environments. Micron 41:1005-1010. 